\title{
PAGO DE SALARIOS CAÍDOS E INDEMNIZACIÓN. UN NUEVO ENFOQUE*
}

\author{
PAYMENT OF FALLEN WAGES AND COMPENSATION. \\ A NEW APPROACH \\ PAIEMENT DES SALARIES TOMBÉS ET INDEMNISATION. \\ UNE NOUVELLE APPROCHE
}

\author{
Alberto Herrera PÉREZ ${ }^{* *}$ \\ Eduardo Alberto HerrerA MONTES***
}

Edfra semper iunctus

\section{TESIS JURISPRUDENCIAL MATERIA DE ANÁLISIS}

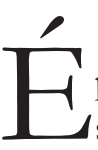

poca: Décima. Registro: 2014106. Instancia: Segunda Sala. Tipo de Tesis: Jurisprudencia. Fuente: Semanario Judicial de la Federación. Publicación: viernes 21 de abril de 2017, 10:25 horas. Materia(s): (Laboral). Tesis: 2a./J. 34/2017 (10a.).

\begin{abstract}
SALARIOS CAÍDOS DE LOS TRABAJADORES BUROCRÁTICOS. EL ARTÍCULO 48 DE LA LEY FEDERAL DEL TRABAJO NO ES APLICABLE SUPLETORIAMENTE A LA LEY FEDERAL DE LOS TRABAJADORES AL SERVICIO DEL ESTADO. El artículo 43, fracción III, de la Ley Federal de los Trabajadores al Servicio del Estado, al establecer el derecho al pago de salarios caídos en favor de los trabajadores que acrediten en juicio haber sido injustamente separados de su fuente de empleo, sin prever un periodo límite para su pago, no constituye una omisión normativa, en tanto la redacción adoptada por el legislador responde a su deseo de reconocerles el acceso a una indemnización plena,
\end{abstract}

\footnotetext{
* Recibido el 29 de mayo de 2017 y aceptado para su publicación el 4 de septiembre de 2017.

** Especialista en derecho constitucional por la Universidad Nacional Autónoma de México.

*** Estudiante de la Licenciatura en Derecho en la Universidad Tecnológica de México.
}

\section{IS Revista Latinoamericana de Derecho Social} Núm. 26, enero-junio de 2018, pp. 229-246 
lo que armoniza con el derecho a una indemnización integral, en términos del artículo 63 de la Convención Americana sobre Derechos Humanos. Así, en atención a la máxima "ahí donde la ley no distingue el juzgador tampoco puede distinguir", se hace patente que no fue voluntad del legislador incluir un tope al pago de salarios caídos en la Ley Federal de los Trabajadores al Servicio del Estado y, por ende, su cálculo debe continuar computándose hasta el cumplimiento del laudo. Por su parte, la reforma al artículo 48, párrafo segundo, de la Ley Federal del Trabajo, publicada en el Diario Oficial de la Federación el 30 de noviembre de 2012, obedeció a circunstancias específicas que, tras la conclusión de un proceso legislativo, condujeron a considerar necesario limitar a 12 meses máximo el pago de salarios vencidos en casos de despido injustificado en un juicio laboral, lo que evidencia que el establecimiento de un plazo límite para su pago fue respuesta expresa a la voluntad legislativa. Por tanto, ante la ausencia de un límite para el pago de salarios caídos en la legislación burocrática, se concluye que el legislador no ha considerado necesario fijarlo pues, de ser así, lo habría realizado como hizo en la Ley Federal del Trabajo. ${ }^{1}$

\section{DELIMITACIÓN ANALÍTICA}

La tesis jurisprudencial 2a./J. 34/2017 (10a.)2 establece criterios contradictorios respecto del contenido y alcance del derecho humano a una indemnización integral condicionando la existencia y observancia de éste a la voluntad del legislador ordinario.

De la tesis sujeta a estudio se desprenden varios temas que serán materia de examen:

- Derecho humano tutelado

- Derecho al trabajo. ${ }^{3}$

- Indemnización o reparación

- Pago de salarios caídos por separación injustificada de la fuente de empleo.

1 Tesis 2a./J. 34/2017 (10a.), Semanario Judicial de la Federación y su Gaceta, Décima Época, t. I, abril de 2017.

2 Jurisprudencia por contradicción de tesis.

3 Declaración Universal de Derechos Humanos, artículo 23: 1. "Toda persona tiene derecho al trabajo, a la libre elección de su trabajo, a condiciones equitativas y satisfactorias de trabajo y a la protección contra el desempleo". 
Esta revista forma parte del acervo de la Biblioteca Jurídica Virtual del Instituto de Investigaciones Jurídicas de la UNAM

- Orden Jurídico

- Convención Americana sobre Derechos Humanos.

- Ley Federal de los Trabajadores al Servicio del Estado reglamentaria del apartado $B$ del artículo 123 constitucional (LFTSE).

- Ley Federal del Trabajo (LFT).

- Supuestos normativos

- La LFTSE omite establecer un período límite para el pago de indemnizaciones.

- La LFT establece un período límite para el pago de indemnizaciones.

- Puntos de examen

-Omisión normativa.

-Indemnización integral.

-Voluntad del legislador.

- Asimetría legislativa.

- Compresión de un derecho humano.

- Interpretación conforme.

- Integración normativa (supletoriedad)

\section{ANÁLISIS}

Entendemos los derechos humanos como aquellos inherentes a toda persona por el sólo hecho de revestirse de tal carácter. "Los derechos humanos, ya sea que deriven de fuente internacional o de la Constitución doméstica, se constituyen como normas paramétricas bajo las cuales debe analizarse la validez de normas o actos de los órganos de poder estatal constituidos (regularidad constitucional)". ${ }^{4}$

En la tesis jurisprudencial a estudio, la segunda sala de la Suprema Corte de Justicia de la Nación (SCJN, la Corte, Suprema Corte, alto tribunal) respecto del contenido del artículo 43 fracción III de la LFTSE ${ }^{5}$ sentenció:

4 Herrera Pérez, Alberto, "Correlación jerárquica normativa de los tratados internacionales en materia de derechos humanos y la Constitución Federal Mexicana", Revista el Tribunal Superior de Justicia del Distrito Federal, año VIII, núm. 22, diciembre de 2015, p. 151.

5 Artículo 43. "Son obligaciones de los titulares a que se refiere el Artículo 1o. de esta Ley: III. Reinstalar a los trabajadores en las plazas de las cuales los hubieren separado y ordenar el pago de los salarios caídos, a que fueren condenados por laudo ejecutoriado. En los casos 
...la redacción adoptada por el legislador responde a su deseo de reconocerles el acceso a una indemnización plena, ${ }^{6}$ lo que armoniza con el derecho a una indemnización integral en términos del artículo 63 de la Convención Americana sobre Derechos Humanos... se hace patente que no fue voluntad del legislador incluir un tope al pago de salarios en la Ley Federal de los Trabajadores al Servicio del Estado y por ende, su cálculo debe continuar computándose hasta el cumplimiento del laudo. Por tanto ante la ausencia de un límite para el pago de salarios caídos en la legislación burocrática, se concluye que el legislador no ha considerado necesario fijarlo pues, de ser así, lo habría realizado como hizo en la Ley Federal del Trabajo.

Por cuanto hace a la reforma del artículo 48, párrafo segundo de la LFT, la Corte reflexiona: “...obedeció a circunstancias específicas que, tras la conclusión de un proceso legislativo, condujeron a considerar necesario limitar a 12 meses máximo el pago de salarios vencidos en casos de despido injustificado en un juicio laboral, lo que evidencia que el establecimiento de un plazo límite para su pago fue respuesta expresa a la voluntad legislativa".

Los puntos relevantes de este criterio jurisprudencial son:

- La indemnización integral es un derecho humano tutelado por la Convención Americana sobre Derechos Humanos (Convención ADH o la Convención) $;^{7}$

- La ausencia en la LFTSE de un periodo límite para el cómputo del pago de salarios caídos de los trabajadores burócratas no es una omisión legislativa en tanto responde a un reconocimiento del legislador al derecho humano a una indemnización integral;

- La indemnización integral para los trabajadores al servicio del Estado se extiende hasta el cumplimiento total del laudo sin restricciones temporales;

de supresión de plazas, los trabajadores afectados tendrán derecho a que se les otorgue otra equivalente en categoría y sueldo".

6 Los realces en letra cursiva son de los autores.

7 Artículo 63. “...1. Cuando decida que hubo violación de un derecho o libertad protegidos en esta Convención, la Corte dispondrá que se garantice al lesionado en el goce de su derecho o libertad conculcados. Dispondrá asimismo, si ello fuera procedente, que se reparen las consecuencias de la medida o situación que ha configurado la vulneración de esos derechos y el pago de una justa indemnización a la parte lesionada". 
- La voluntad del legislador en el caso de los salarios caídos, normados por la LFT, fue establecer un periodo límite para su pago, y

- No es aplicable supletoriamente la LFT a la LFTSE en el caso del periodo límite para el pago de salarios vencidos.

\section{Indemnización o reparación del daño}

El concepto de indemnización o reparación a la víctima por violación a los derechos humanos ha sido interpretado por la Corte Interamericana de Derechos Humanos (Corte IDH) de la forma siguiente:

En caso de violación a los derechos humanos, el Estado deberá reparar a las víctimas de acuerdo con los estándares que al efecto se han establecido en el derecho internacional de los derechos humanos.

Para articular esta obligación, la Corte IDH ha tomado como base lo dispuesto en el artículo 63.1 de la Convención Americana, y ha indicado que toda violación de una obligación internacional que haya producido daño comporta el deber de repararlo adecuadamente; y que esa disposición "recoge una norma consuetudinaria que constituye uno de los principios fundamentales del Derecho Internacional contemporáneo sobre responsabilidad de un Estado".

A pesar de que el concepto de "reparación integral" (restitutio in integrum), que implica el restablecimiento de la situación anterior y la eliminación de los efectos que la violación produjo, es el eje orientador de las medidas de reparación que dicta la Corte IDH, el mismo Tribunal ha tomado en cuenta situaciones en donde resulta necesario ir más allá de esa simple restitución. Esto se dio, por ejemplo, en el Caso Gonzálezy Otras ("Campo Algodonero") vs. México, en donde la discriminación estructural en la que se enmarcan los hechos del asunto requiere que las reparaciones tengan una vocación transformadora de dicha situación, de tal forma que las mismas tengan un efecto no sólo restitutivo sino también correctivo, al no resultar lógica la restitución a la misma situación estructural de violencia y discriminación. ${ }^{8}$

...cuando se ordenan reparaciones de conformidad con el artículo 63 de la Convención, la Corte Interamericana persigue el estándar del restitu-

8 Fundación Konrad Adenauer Stiftung, Convención Americana sobre Derechos Humanos, Comentada, México, Suprema Corte de Justicia de la Nación, 2014, pp. 53 y 54, disponible en: https://www.sitios.scjn.gob.mx/codhap/sites/default/files/acc_ref/Convencion_Americana_sobre_Derechos_final.pdf. 
tio in integrum. Esta sólida norma del derecho internacional "consiste en el restablecimiento de la situación anterior a la violación”. El artículo 63.1 otorga a la Corte el mandato extenso de buscar un restitutio in integrum, que exige una "justa indemnización” y aún más: la Corte dispondrá que se garantice al lesionado en el goce de su derecho o libertad conculcados. Dispondrá asimismo, si ello fuera procedente, que se reparen las consecuencias de la medida o situación que ha configurado la vulneración de esos derechos... ${ }^{9}$

De los criterios transcritos desprendemos que para la Corte IDH, la indemnización o restitución integral (restitutio in integrum), de conformidad con el artículo 63 de la Convención ADH, comprende:

- Justa indemnización;

- Restablecimiento de la situación anterior a la violación;

- Eliminación de los efectos que la violación produjo;

- Garantizar a la víctima el goce en el derecho o libertad conculcado, y

- Reparación de las consecuencias del acto violatorio de derechos.

Los criterios de la Corte $\mathrm{IDH}^{10}$ sobre la indemnización integral inserta en el artículo 63 de la Convención son compartidos por la Suprema Corte al interpretar que la omisión de establecer en la LFTSE un plazo límite para el pago de los salarios caídos hasta el cumplimiento final del laudo responde al deseo del legislador de reconocer a los trabajadores burocráticos: “...una indemnización plena, que armoniza con el derecho a una indemnización integral, en términos del artículo 63 de la Convención Americana sobre Derechos Humanos".

Observemos, la no limitación legal al periodo de pago de los salarios vencidos para los trabajadores al servicio del Estado es interpretado por la Corte como un reconocimiento legislativo al derecho humano a la indemnización integral, ergo, la limitación a este periodo permite entender su potencial violación.

\footnotetext{
9 Ibidem, p. 268.

10 Respecto de las opiniones de tribunales supranacionales, la Corte ha sostenido la Tesis 1a. CCCXLIV/2015, Semanario Judicial de la Federación y su Gaceta, Décima Época, t. I, noviembre de 2015, p. 986.
} 


\section{Ley federal del trabajo}

El criterio jurisprudencial en estudio alcanza matices contradictorios en el caso de la LFT al señalar: “...la reforma al artículo 48, párrafo segundo, de la Ley Federal del Trabajo, obedeció a circunstancias específicas que, tras la conclusión de un proceso legislativo, condujeron a considerar necesario limitar a 12 meses máximo el pago de salarios vencidos en casos de despido injustificado en un juicio laboral, lo que evidencia que el establecimiento de un plazo límite para su pago fue respuesta expresa a la voluntad legislativa".

En la lógica de la Corte, el respeto al derecho humano a la reparación o indemnización integral queda al arbitrio parlamentario, en otras palabras, si el legislador no limita el periodo de pago de los salarios vencidos, lo hace por respeto al derecho humano a una indemnización integral (LFTSE); y si limita este mismo derecho, obedece a circunstancias específicas (LFT).

No debemos olvidar que el legislador, en ejercicio de su facultad constitucional, tiene como marco de actuación la protección y el respeto a los derechos humanos, ${ }^{11}$ careciendo de poderes omnímodos, cuya aplicación pudiera atropellarlos o limitarlos arbitrariamente:

Las leyes no son "constitucionales" por el hecho de haber sido expedidas en cumplimiento de las formalidades previstas en el ordenamiento. También deben estar materialmente en consonancia tanto con los elevados valores fundamentales del ordenamiento fundamental liberal democrático, como con el orden de valores constitucionales, pero también deben satisfacer los principios constitucionales elementales no escritos, así como las directrices fundamentales de la Ley Fundamental, especialmente el principio del Estado de Derecho y el principio del Estado social. ${ }^{12}$

... gracias al sometimiento al derecho de la producción del derecho mismo, es el propio deber ser del derecho y no sólo su ser — su modelo normativo y no sólo su existencia, las opciones sustanciales que guían su producción y no sólo sus formas de producción — lo que ha sido positivizado como derecho sobre el derecho, dirigido a limitar y a vincular los contenidos de la legislación a los principios constitucionales. Al mismo tiempo, esta do-

11 Tesis: P./J. 11/2016, Semanario Judicial de la Federación y su Gaceta, Décima Época, t. I, septiembre de 2016, p. 52.

12 Fundación Konrad Adenauer, Stiftung, Jurisprudencia del Tribunal Constitucional Federal Alemán, extractos de las sentencias más relevantes compiladas por Jürgen Schwabe, Berlín, 2009, p. 58. 
ble positivización — del ser del derecho y de su deber ser jurídico— equivale a la completa realización y a la ampliación del estado de derecho, pues el legislador deja de ser omnipotente y queda igualmente subordinado a la ley constitucional, no sólo en lo que atañe a las formas de producción jurídica sino también en lo relativo a los contenidos normativos producidos. ${ }^{13}$

En el caso a estudio el legislador ordinario protege y respeta el derecho a una indemnización integral de los trabajadores burocráticos al no establecer en la LFTSE una limitación al periodo para el pago de salarios caídos, sin embargo, para este mismo tema en la LFT el legislador no mantiene el mismo criterio tutelar y limita este período eludiendo la observancia del derecho a una indemnización integral la cual debe ser el eje rector en toda reparación del daño en el caso de violaciones a derechos humanos, conforme lo ha interpretado en reiterados criterios la Corte IDH.

Entendemos que los derechos humanos no son absolutos y el legislador puede comprimir el ejercicio de los mismos, sin embargo, esto lo debe hacer atendiendo al principio de proporcionalidad o razonabilidad ${ }^{14} \mathrm{el}$ cual tiene su fundamento en el principio del Estado de derecho y en la esencia de los derechos fundamentales que, como expresión del derecho general del ciudadano a la libertad frente al Estado, sólo puede ser limitado en forma amplia por el poder público cuando ello sea indispensable..$^{15}$

La aplicación del principio de proporcionalidad contribuye a la justa solución de los conflictos que enfrentan los derechos fundamentales y otros principios constitucionales, entre sí o con otros bienes jurídicos promovidos por una medida legislativa o administrativa que incida en la efectividad de aquéllos... el principio de proporcionalidad cumple una función argumentativa en la interpretación de los principios fundamentales afectados en un caso concreto, para determinar el significado preciso de las disposiciones constitucionales que los contienen... para establecer los límites de la relación entre dos bienes jurídicos — sobre todo si son de carácter constitucional— es indispensable aplicar el principio de proporcionalidad, pues por la precisión de concep-

13 Ferrajoli, Luigi, Garantísmo. Una discusión sobre derecho y democracia, Madrid, Trotta, 2006, p. 28.

14 Tesis 1a. CCCLXXXV/2014, Semanario Judicial de la Federación y su Gaceta, Décima Época, t. I, noviembre de 2014, p. 719.

15 Fundación Konrad Adenauer, Stiftung, Jurisprudencia del Tribunal Constitucional Federal Alemán, op. cit., p.150. 
tos, ideas y situaciones que aporte a los casos concretos, es un instrumento metodológico apropiado para establecer si es legítima una medida legislativa que necesariamente debe promover un bien público en que intervienen los derechos fundamentales. ${ }^{16}$

En el caso de las reformas de 2012 a la LFT, las circunstancias argumentadas para limitar el periodo de pago de los salarios caídos, se consideran carentes de correspondencia lógica y proporcional respecto de la compresión del derecho humano a la indemnización integral, lo que vulnera el principio de proporcionalidad o razonabilidad. Fundemos esta afirmación.

En la exposición de motivos de la reforma a la LFT del mes de noviembre de 2012, específicamente por cuanto hace al artículo 48, párrafo segundo, el Ejecutivo Federal sostuvo:

Establecer un límite a la generación de salarios vencidos para combatir la indebida práctica de prolongar artificialmente la duración de los procedimientos laborales. Se prevé que se generarán solamente entre la fecha del despido y hasta por un periodo máximo de doce meses. Una vez concluido este periodo, si el juicio aún no se ha resuelto, se generaría solamente un interés.

Con esta fórmula, se estima que se preserva el carácter indemnizatorio de los salarios vencidos y también se atiende la necesidad de conservar las fuentes de empleo, a la par de que se contribuye a la disminución — de manera sustancial— de los tiempos procesales para resolver los juicios.

Las circunstancias específicas que motivaron el establecimiento de un límite al periodo de pago de los salarios caídos son:

- Combatir la prolongación artificial de la duración de los procedimientos laborales;

- Conservar las fuentes de empleo, y

- Disminuir los tiempos procesales para resolver los juicios.

Ciertamente, como señala la iniciativa, se preservó “el carácter indemnizatorio" del pago de los salarios vencidos, pero se dejó fuera el aspecto "in-

16 Sánchez Gil, Rubén, Elprincipio de proporcionalidad, Instituto de Investigaciones Jurídicas, México, 2007, pp. 2, 20 y 22. 
tegral". Establecer una indemnización cualquiera o inequitativa no respeta el criterio de la Corte IDH, la indemnización debe ser integral para cumplir con su naturaleza y fines, en caso contrario, se hace nugatoria la justa reparación nacida de la violación a un derecho humano.

Es un principio de derecho internacional, que la jurisprudencia ha considerado - incluso una concepción general del derecho — que toda violación a una obligación internacional que haya producido un daño comporta el deber de repararlo adecuadamente... La reparación del daño ocasionado por la infracción de una obligación internacional consiste en la plena restitución (restitutio in integrum); lo que incluye el restablecimiento de la situación anterior y la reparación de las consecuencias que la infracción produjo y el pago de una indemnización como compensación por los daños patrimoniales y extrapatrimoniales incluyendo el daño moral. ${ }^{17}$

Época: Décima. Registro: 2014098. Instancia: Primera Sala. Tipo de Tesis: Jurisprudencia. Fuente: Semanario Judicial de la Federación. Publicación: viernes 21 de abril de 2017 10:25 horas. Materia(s): (Constitucional). Tesis: 1a./J. 31/2017 (10a.).

DERECHO FUNDAMENTAL A UNA REPARACIÓN INTEGRAL O JUSTA INDEMNIZACIÓN. SU CONCEPTO Y ALCANCE. El derecho citado es un derecho sustantivo cuya extensión debe tutelarse en favor de los gobernados, por lo que no debe restringirse innecesariamente. Ahora bien, atento a los criterios emitidos por la Corte Interamericana de Derechos Humanos, el derecho a la reparación integral permite, en la medida de lo posible, anular todas las consecuencias del acto ilícito y restablecer la situación que debió haber existido con toda probabilidad, si el acto no se hubiera cometido, y de no ser esto posible, procede el pago de una indemnización justa como medida resarcitoria por los daños ocasionados, lo cual no debe generar una ganancia a la víctima, sino que se le otorgue un resarcimiento adecuado. En ese sentido, el derecho moderno de daños mira a la naturaleza y extensión del daño a las víctimas y no a los victimarios. Así, el daño causado es el que determina la naturaleza y el monto de la indemnización, de forma que las reparaciones no pueden implicar enriquecimiento ni empobrecimiento para la víctima o sus sucesores; además, no se pretende que la responsabilidad sea excesiva, ya que debe subordinarse a requisitos cualitativos. Por otro lado, una indemnización será excesiva cuando exceda del monto suficiente para compensar

17 Corte Interamericana de Derechos Humanos, Caso Velásquez Rodríguez vs. Honduras. Sentencia de 21 de julio de 1989 (reparaciones y costas) párrafos 25 y 26. 
a la víctima, sin embargo, limitar la responsabilidad fijando un techo cuantitativo implica marginar las circunstancias concretas del caso, el valor real de la reparación o de la salud deteriorada; esto es, una indemnización es injusta cuando se le limita con topes o tarifas, y en lugar de ser el Juez quien la cuantifique justa y equitativamente con base en criterios de razonabilidad, al ser quien conoce las particularidades del caso, es el legislador quien, arbitrariamente, fija montos indemnizatorios, al margen del caso y de su realidad. ${ }^{18}$

El argumento relativo a que la inexistencia de un límite para el pago de salarios caídos prolonga de manera artificial los procedimientos laborales es completamente falaz, y no puede ser más que ilusorio para justificar la limitación en el periodo del pago de salarios caídos, pues no es al trabajador a quien beneficia el interminable procedimiento laboral, hacerlo responsable de los vicios de este procedimiento es pasar inadvertidas la falta de ética y responsabilidad de los servidores públicos de las Juntas de Conciliación y Arbitraje, quienes con total indolencia hacia la justicia obrera, permiten que transcurran largos periodos de tiempo antes de dictar el laudo respectivo, sin olvidar la incumplida obligación del Estado de impartir una justicia pronta y expedita o bien, la estrategia empresarial de "cansar al trabajador" para que finalmente acepte un arbitrario e inequitativo arreglo.

La eficacia, oportunidad y veracidad de las "circunstancias específicas" para limitar en la LFT el periodo de pago de los salarios caídos, en el 2012, se ven ampliamente contradichas por las razones establecidas en la exposición de motivos de la iniciativa de reforma constitucional en materia de justicia laboral, referente a los artículos 107 y 123, presentada por el Ejecutivo Federal en el mes de abril de 2016:

Los cambios introducidos en la justicia laboral ${ }^{19}$ se sustentaron fundamentalmente en el establecimiento de mecanismos para eficientar los procedimientos acortando tiempos para que la justicia sea una realidad, y en la profesionalización del personal encargado de impartirla. No obstante, después

18 Adviértase como para la SCJN el derecho a una reparación o indemnización integral es un derecho fundamental.

19 Se refiere a las reformas publicadas en el Diario Oficial de la Federación el 30 de noviembre de 2012. 
de tres años y como resultado de concienzudas evaluaciones y análisis presentados en diversos foros, se arriba a la conclusión que se requieren transformaciones cualitativas para que la justicia laboral cumpla su propósito.

Esta iniciativa ${ }^{20}$ está dirigida a acabar con todo espacio susceptible de prohijar inercias, vicios y prácticas que durante el desarrollo de un conflicto laboral dan lugar a la incertidumbre jurídica.

Se debe eliminar todo elemento que convierta a la justicia laboral en lenta, costosa, de difícil acceso y cuestionable, así como combatir la parcialidad, simulación, discrecionalidad y opacidad.

De acuerdo con los resultados obtenidos en la consulta elaborada por el Centro de Investigación y Docencia Económica (CIDE), en preparación de los Diálogos por la Justicia Cotidiana, las modificaciones normativas en la materia no han generado una percepción de cambio significativo.

Desde el punto de vista de la estructura de los órganos de impartición de justicia, la consulta reveló la necesidad de valorar la situación actual de las Juntas de Conciliación y Arbitraje. A decir de los expertos, la revisión de este tipo de impartidores de justicia, debe incluir, entre otros aspectos relevantes, analizar la autonomía y sus formas de integración tripartita.

La intención primordial de las propuestas se encamina a transformar, a profundidad, tanto los incentivos perversos que subsisten en el marco legal vigente, como los procedimientos y actuaciones de las instituciones del Estado encargadas de impartir la justicia laboral, factores que boy constituyen una limitante para que ésta llegue con la celeridad, economía y seguridad que demandan los ciudadanos.

Precisamente, las reformas que se proponen en esta iniciativa buscan consolidar la autonomía y eficacia en la impartición de justicia. Se trata de atender un reclamo social de primer orden, frente a la innegable necesidad de modernización del sistema hasta ahora vigente. Se trata, sin lugar a dudas, de la reforma más importante en la materia desde la promulgación de la Carta Magna de 1917.

La exposición de motivos transcrita no deja lugar a dudas, la reforma a la LFT del 2012 no resultó eficaz para combatir los vicios dentro del procedimiento laboral que se pretendían combatir (prolongación artificial de los procedimientos laborales y disminución de los tiempos procesales para resolver los juicios) y que tuvieron como consecuencia limitar el período para el pago

20 Se refiere a la iniciativa de reformas a la Constitución de abril de 2016. 
de salarios vencidos ${ }^{21}$ en evidente transgresión al derecho humano a una indemnización integral. ${ }^{22}$

\section{Interpretación conforme y principio pro homine}

El artículo 1o. constitucional, reformado en el 2011, establece en su primer párrafo el goce de los derechos humanos reconocidos por la Constitución Política de los Estados Unidos Mexicanos y los tratados internacionales (elementos intraconstitucionales) ${ }^{23}$ suscritos por nuestro país; el segundo, refiere que la interpretación normativa respecto de estos derechos se realizará conforme a la Constitución y los tratados internacionales en esta materia, aplicando las disposiciones que en todo tiempo brinden a la persona la protección más amplia. Esta expansión interpretativa, en el caso de los derechos humanos, hace posible la observancia de herramientas jurídicas de naturaleza materialmente constitucional, amplificadoras del espectro protector de las normas tutelares de esos derechos que no se encuentran establecidos de manera expresa dentro del texto constitucional (elementos supra y paraconstitucionales). ${ }^{24}$

21 Recordemos que el 24 de febrero de 2017 se publicó en el Diario Oficial de la Federación el decreto por el que se declaran reformadas y adicionadas diversas disposiciones de los artículos 107 y 123 de la Constitución Política de los Estados Unidos Mexicanos, en materia de Justicia Laboral.

22 Las reformas a la LFT que originaron la limitación al período de pago de salarios vencidos, desde su inicial invocación, fueron ilógicas e ineficaces para alcanzar el propósito pretendido, entiéndase, la falta de un límite temporal para el pago de salarios caídos no es fuente de los vicios que falazmente se le atribuyen, si esta fuera la lógica, la legislación burocrática (en la cual no existen topes) debió igualmente reformarse para limitar el período de pago de salarios vencidos y esto no fue así (Ubi eadem ratio, eadem dispositio). En este tema los propios ministros de la segunda sala de la SCJN no logran una pacífica y unánime opinión, baste observar la jurisprudencia emanada de la contradicción de tesis derivada de criterios opuestos relativos a la violación de derechos humanos con motivo de la reforma al artículo 48 párrafo segundo de la LFT la cual fue resuelta por mayoría de tres votos a favor y dos en contra (sin dejar de hacer notar que en esta tesis no se realizó ningún análisis del derecho humano a la indemnización integral). Tesis: 2a. /J. 28/2016, Semanario Judicial de la Federación y su Gaceta, Décima Época, marzo de 2016.

23 Característica que les corresponde por su mención expresa en el texto fundamental. Herrera Pérez, Alberto, "El bloque de constitucionalidad y los derechos humanos", Revista El Tribunal Superior de Justicia del Distrito Federal, año VIII, núm. 22, diciembre de 2015, p. 121.

24 Los elementos supraconstitucionales se integran por criterios jurídicos, jurisprudenciales u opiniones de órganos, tribunales o cortes internacionales (Comisión Interamericana de Derechos Humanos, Corte Interamericana de Derechos Humanos, Corte Europea de Derechos Humanos, Corte Internacional de Justicia, Corte Penal Internacional [en el 
El segundo párrafo del artículo 1o. constitucional establece: "Las normas relativas a los derechos humanos ${ }^{25}$ se interpretarán de conformidad con esta Constitución y con los tratados internacionales de la materia favoreciendo en todo tiempo a las personas la protección más amplia”.

El mandato del Poder reformador, en el sentido de establecer que la interpretación conforme las normas relativas a los derechos humanos debe realizarse no sólo siguiendo el texto de la Constitución, sino de los tratados internacionales, permite afirmar categóricamente que estos instrumentos jurídicos de fuente internacional se sitúan en el mismo rango jerárquico que nuestra ley fundamental. ${ }^{26}$

De acuerdo a lo anterior, y atendiendo a la interpretación "conforme", los criterios de la Corte IDH sobre el derecho humano a una indemnización o reparación integral deben ser de aplicación preferente por su amplitud tutelar. ${ }^{27}$

No debemos olvidar que los derechos humanos: “...están por encima del Estado y su soberanía y no puede considerarse que se violenta el principio de no intervención cuando se ponen en movimiento los mecanismos organizados por la comunidad internacional para su promoción y protección". ${ }^{28}$

caso de esta última al ser potestativo para el Estado mexicano el reconocimiento de su jurisdicción pudiera existir resistencia en adoptar sus criterios u opiniones jurídicas]), etcétera. Los elementos paraconstitucionales (elementos que sin encontrarse formalmente incluidos en la Constitución subyacen en su texto no necesariamente expresados materialmente en el mismo y que recogen los fundamentos que inspiraron al Constituyente para diseñar la estructura fundamental del Estado mexicano, la motivación política de la normatividad, las metas hacia las cuales el Estado debe orientar sus acciones, el rumbo de las instituciones jurídicas así como los valores que la Constitución aspira a realizar y que trasciende la mera literalidad de sus artículos) se conforman por: principios y valores de jerarquía formalmente constitucional (libertad, justicia, vida, seguridad, etcétera), y documentos provenientes de los procesos parlamentarios o legislativos de adición, reforma o derogación del texto Constitucional (Diario de los Debates, Gaceta Parlamentaria, exposición de motivos, dictámenes parlamentarios, formas de participación ciudadana [como elementos de expresión directa de la soberanía del pueblo: referéndum, plebiscito, consulta popular etcétera]). Herrera Pérez, Alberto, "El bloque de constitucionalidad...", cit., p. 121.

25 Adviértase que la Constitución no circunscribe la interpretación a aquellas normas cuya materia sea exclusiva a derechos humanos, al utilizar el adjetivo "relativas" (cuyo significado es lo que está en relación) permite la interpretación de aquellas normas que tangencial o indirectamente tutelan estos derechos.

26 Herrera Pérez, Alberto, “Correlación jerárquica...”, cit., p. 149.

27 Tesis P./J. 21/2014, Semanario Judicial de la Federación y su Gaceta, Décima Época, t. I, abril de 2014, p. 204.

28 Nikken, Pedro, Sobre el concepto de derechos humanos, Costa Rica, Seminario sobre derechos 
En este tema recordemos el principio pro homine el cual obliga al operador jurídico a realizar la interpretación más amplia y favorable para la persona.

De igual manera, no debemos dejar de considerar la observancia del principio constitucional pro homine o pro personae, que exige tener en cuenta en todo tiempo la aplicación de la norma orientada a favorecer a las personas con la protección más amplia, ${ }^{29}$ lo que implica una observancia normativa con independencia de su fuente (nacional o internacional), jerarquía o restricciones que limiten el ejercicio de los derechos humanos.

Estimamos que el reconocimiento y alcance otorgado por el artículo 1 o. constitucional a las normas internacionales en materia de derechos humanos les confiere la fuerza y observancia obligatoria para alcanzar una igualdad jerárquica normativa con la Constitución, autorizándoles a integrar lagunas normativas, fundar interpretaciones extensivas, y aún, en ciertos casos, aplicarse de manera prevalente a nuestra ley fundamental.

Como corolario, la interpretación de la Corte IDH respecto del derecho humano a la indemnización integral permite entender que el artículo 48 párrafo segundo de la LFT, al establecer un periodo límite para el pago de los salarios vencidos es inconvencional al violar el contenido y alcance del artículo 63 de la Convención Americana sobre Derechos Humanos. ${ }^{30}$

\section{Supletoriedad}

En la tesis jurisprudencial a estudio se observan matices que pudieran considerarse parciales hacia el sector burócrata alcanzando un plus al momento en que la SCJN desestima la aplicación supletoria de la Ley Federal del Trabajo no obstante que por disposición expresa de la Ley Federal de los Trabajadores al Servicios del Estado, reglamentaria del apartado B del artículo 123 constitucional (artículo 11), aquella es supletoria de ésta. ${ }^{31}$

humanos, Instituto Interamericano de Derechos Humanos, 1997, p. 17, disponible en: https:// www.iidh.ed.cr/IIDH/media/1995/seminario-ddhh-babana-1997.pdf, consultado el 29 de mayo de 2017.

29 “...el haber acordado rango constitucional a determinadas normas internacionales, merced a la técnica jurídica del bloque de constitucionalidad, ha servido para que las normas legales puedan ser interpretadas no sólo de conformidad con la Constitución, sino a la luz de la legalidad internacional." Ramelli, Alejandro, op. cit., nota 14, p.168.

30 Tesis IV.2o.A. J/7, Semanario Judicial de la Federación y su Gaceta, Décima Época, t. II, diciembre de 2013, p. 933.

31 Artículo 11. "En lo no previsto por esta ley o disposiciones especiales, se aplicarán 
Preocupante la postura de la Corte al apartarse de lo previsto en la LFTSE e interpretar de manera sui generis el sentido, alcance y aplicación de la supletoriedad de la Ley Federal del Trabajo ${ }^{32}$ respecto del período límite del pago de salarios caídos: “... ante la ausencia de un límite para el pago de salarios caídos en la legislación burocrática, se concluye que el legislador no ha considerado necesario fijarlo pues, de ser así, lo habría realizado como hizo en la Ley Federal del Trabajo".

Bajo este criterio jurisprudencial estaría condenada a desaparecer la figura de la heterointegración o supletoriedad, en razón de que, ante la inexistencia u omisión en el texto legal de una regulación para un supuesto normativo específico, se argumentaría llanamente que el legislador ha considerado innecesario establecerlo "pues, de ser así, lo habría realizado", olvidando que cuando la referencia de una ley a otra es expresa, debe entenderse que la aplicación de la norma supletoria se hace en los supuestos no contemplados, posibles omisiones o en la interpretación de disposiciones ausentes en la ley objeto de supletoriedad.

\section{CONCLUSIONES}

Primera: La indemnización integral como reparación a la violación de un derecho fundamental es tutelada por la Convención Americana sobre Derechos Humanos.

Segunda: La indemnización integral derivada de los salarios vencidos es un derecho humano.

Tercera: La indemnización integral en el caso de violaciones al derecho humano al trabajo comprende, para los trabajadores burocráticos, el pago de salarios vencidos hasta el cumplimiento total de laudo.

Cuarta: El legislador en el caso de los trabajadores al servicio del Estado respetando el derecho humano a una indemnización integral no estableció en

supletoriamente, y en su orden, la Ley Federal del Trabajo, el Código Federal de Procedimientos Civiles, las leyes del orden común, la costumbre, el uso, los principios generales de derecho y la equidad".

32 Tesis 2a./J. 34/2013, Semanario Judicial de la Federación y su Gaceta, Décima Época, t. II, marzo de 2013, p. 1065. 
la Ley Federal de los Trabajadores al Servicios del Estado, reglamentaria del apartado $B$ del artículo 123 constitucional un periodo límite para el pago de salarios vencidos.

Quinta: Para los trabajadores normados por la Ley Federal del Trabajo el legislador estableció un período límite para el pago de los salarios caídos limitando los fines y alcances del derecho humano a una indemnización integral.

Sexta: La limitación o disminución injustificada o desproporcional del derecho humano a una indemnización integral además de una inconstitucionalidad genera una inconvencionalidad.

Séptima: De subsistir el criterio sustentado por la Suprema Corte de Justicia de la Nación respecto de la supletoriedad normativa es muy posible que se condene a la inoperancia o inexistencia de esta figura.

Octava: A igual razón igual disposición, no pueden existir consideraciones desiguales para sujetos inmersos en el mismo supuesto jurídico (en el caso el pago de una indemnización), el legislador debe guardar simetría en el trabajo parlamentario en la adecuada tutela de idénticos derechos fundamentales.

\section{FUENTES DE CONSULTA}

Corte Interamericana de Derechos Humanos, Caso Velásquez Rodríguez. vs. Honduras, sentencia de 21 de julio de 1989 (reparaciones y costas).

Ferrajoli, Luigi, Garantísmo, Una discusión sobre derecho y democracia, Trotta, Madrid, 2006.

Fundación Konrad Adenauer Stiftung, Convención Americana sobre Derechos Humanos, Comentada, México, Suprema Corte de Justicia de la Nación, 2014.

Fundación KonRAD AdenAuER STIFTUnG, Jurisprudencia del Tribunal Constitucional Federal Alemán, extractos de las sentencias más relevantes compiladas por Jürgen Schwabe, Berlín, 2009.

Herrera PÉrez, Alberto, “Correlación jerárquica normativa de los tratados internacionales en materia de derechos humanos y la Constitución Federal Mexicana", Revista el Tribunal Superior de Justicia del Distrito Federal, año VIII, núm. 22, diciembre de 2015. 
Herrera PÉREZ, Alberto, "El bloque de constitucionalidad y los derechos humanos", Revista El Tribunal Superior de Justicia del Distrito Federal, año VIII, núm. 22, diciembre de 2015.

NikKen, Pedro, Sobre el concepto de derechos humanos, Costa Rica, Seminario sobre Derechos Humanos, Instituto Interamericano de Derechos Humanos, 1997, disponible en: https:/ / www.ïdh.ed.cr/IIDH/media/1995/seminario-ddhb-habana-1997.pdf.

SÁNCHEZ GIL, Rubén, El principio de proporcionalidad, México, Instituto de Investigaciones Jurídicas, 2007.

Suprema Corte de Justicia de la NACión, Tesis 1a. CCCLXXXV/2014, Semanario Judicial de la Federación y su Gaceta, Décima Época, t. I, noviembre de 2014.

Suprema Corte de Justicia de la NACión, Tesis 1a. CCCXLIV/2015, Semanario Judicial de la Federación y su Gaceta, Décima Época, t. I, noviembre de 2015.

Suprema Corte de Justicia de la Nación, Tesis: 2a./J. 34/2013, Semanario Judicial de la Federación y su Gaceta, Décima Época, t. II, marzo de 2013.

Suprema Corte de Justicia de la Nación, Tesis IV.2o.A. J/7, Semanario Judicial de la Federación y su Gaceta, Décima Época, t. II, diciembre de 2013, p. 933.

Suprema Corte De Justicia de la NAción, Tesis P./J. 11/2016, Semanario Judicial de la Federación y su Gaceta, Décima Época, t. I, septiembre de 2016.

Suprema Corte de Justicia de la NAción, Tesis P./J. 21/2014, Semanario Judicial de la Federación y su Gaceta, Décima Época, t. I, abril de 2014. TS 